\title{
GENETIC AND DEMOGRAPHIC RESPONSES OF MERCURY-EXPOSED MOSQUITOFISH (GAMBUSIA HOLBROOKI) POPULATIONS: TEMPORAL STABILITY AND REPRODUCTIVE COMPONENTS OF FITNESS
}

\author{
Christopher Paul Tatara, + Margaret Mulvey, $\$$ and Michael C. Newman \\ $\dagger$ National Marine Fisheries Service, Manchester Research Station, P.O. Box 130, Manchester, Washington 98353, USA \\ $\ddagger$ The College of William and Mary, Virginia Institute of Marine Science, School of Marine Science, Route 1208 Greate Road, \\ Gloucester Point, Virginia 23062-1346, USA
}

(Received 2 August 2001; Accepted 28 March 2002)

\begin{abstract}
Two previous mesocosm studies showed changes in glucosephosphate isomerase-2 (Gpi-2) allele frequencies in mosquitofish populations exposed to mercury for $111 \mathrm{~d}$ or two years. A previous selection component analysis of single-generation populations exposed for $111 \mathrm{~d}$ to $18 \mu \mathrm{g} / \mathrm{L} \mathrm{Hg}$ suggested that female sexual selection and fecundity selection could contribute to changes in Gpi-2 allele frequencies. The present multigeneration study was conducted to determine the stability of Gpi-2 allele frequencies over four years of mercury exposure, measure the reproductive fitness of Gpi-2 genotypes inhabiting control and mercury-contaminated mesocosms to determine a mechanism explaining changes in Gpi-2 allele frequencies, investigate differences in the demographic characteristics of mercury-exposed and control populations, and investigate the water quality of the mesocosms to determine if variables other than mercury show concordant patterns among mesocosms. Differences in Gpi-2 allele frequencies between control and mercury-exposed populations were stable over four years ( eight generations) of mercury exposure. Mercuryexposed female mosquitofish had a lower probability of being gravid than control females $(p=0.001)$. Mercury-exposed females also had lower fecundity (total number of eggs and embryos) than control females $(p=0.036)$. Unlike the results of the more intense mercury exposures in the single generation study, no strong evidence was found that Gpi-2 genotype influenced fecundity or the probability of being gravid in both control and mercury-exposed females. The quantification of fitness components is difficult but has the potential to enhance our understanding of how toxicants alter allele frequencies in exposed populations.
\end{abstract}

Keywords-Gambusia holbrooki Genetics Mercury Selection Fitness

\section{INTRODUCTION}

The use of allozymes as genetic markers for detecting population-level effects of toxicant exposure is gaining popularity in ecotoxicology. Changes in genotype or allele frequencies have been correlated with environmental contamination in several studies of natural and experimental populations [1-8]. Populations inhabiting contaminated environments frequently have different genotype and allele frequencies than reference or control populations. Researchers studying contaminant-impacted populations often fail to identify any underlying mechanism or population process that explains the differences in genotype and/or allele frequencies among populations [9]. If a mechanism is proposed, it is usually differential survival (viability selection) of allozyme genotypes [9]. Differential survival in field populations is often inferred from laboratory experiments involving exposure to acute toxicant concentrations [2-4]. Endler [10] noted that population biologists tend to focus on differential survival in selection studies to the neglect of equally important differences in reproductive fitness.

If selective agents in the form of environmental contaminants and not random processes (e.g., drift, founder effects) were responsible for the observed changes in the genetic composition of exposed populations, a more complete investigation of the mode of selection should be conducted. Selection can take place at several stages in the life cycle of sexually reproducing organisms, with survival from zygote to adult being

* To whom correspondence may be addressed (chris.p.tatara@noaa.gov). only one component of selection. Additional selection components involve aspects of reproduction and include fecundity selection, male and female sexual selection, and gametic selection $[10,11]$. In population genetics studies where selection is measured, the reproductive components of fitness commonly have a greater influence than the survival component of fitness $[10,11]$.

Our previous study [8] detected changes in the genetic composition of mosquitofish populations at the Gpi-2 locus over the course of a two-year, low-level mercury exposure in mesocosms. The frequency of the Gpi-2 ${ }^{100}$ allele decreased, while the frequency of the $G p i-2^{66}$ allele increased, in mercury-exposed populations relative to the initial and control allele frequencies. The lack of gravid females in the sample precluded investigation of reproductive selection components. We assumed that differences in reproductive fitness among Gpi-2 genotypes played a role in changing allele frequencies in the mercury-exposed populations. Evidence supporting this assumption included a study by Mulvey et al. [5], which identified female sexual selection and fecundity selection at the Gpi-2 locus in mesocosm populations of mosquitofish exposed to mercury for $111 \mathrm{~d}$. Mercury-exposed female mosquitofish homozygous for the Gpi-2 ${ }^{100}$ allele had a lower probability of being gravid, and when they were gravid, they had fewer developing embryos than females of other Gpi-2 genotypes [5]. Mulvey et al. [5] exposed a single generation with weekly additions of mercury to a concentration of $18 \mu \mathrm{g} / \mathrm{L}$ for $111 \mathrm{~d}$.

Because allozymes are being used increasingly for biomonitoring $[12,13]$, it is important to carefully assess their suitability for that purpose. Several studies have documented 
changes in the genetic composition of populations exposed to contaminants but have not investigated the stability of the changes over time through repeated sampling [1-8]. For allozymes to be of practical use, the contaminant-correlated changes in genotype and allele frequencies should not be ephemeral. Allozyme studies also need to examine other important environmental variables (e.g., temperature, salinity) that have been demonstrated to be selective agents in some systems [14,15]. Failure to investigate additional variables might permit the erroneous conclusion that contaminants are the sole cause for the observed changes in a population's genetic structure.

The current study was conducted with four goals in mind. The first was to determine whether the changes in allele frequencies at the Gpi-2 locus in mosquitofish populations were stable over four years ( eight generations) of mercury exposure. The second was to investigate the reproductive fitness of Gpi-2 genotypes inhabiting control and mercury-contaminated mesocosms in order to determine the mechanisms underlying the changes in Gpi-2 allele frequencies. The third was to investigate differences in the demographic characteristics of mercury-exposed and control populations. The last was to investigate common water quality parameters in the mesocosms to determine if variables other than mercury contamination showed concordant patterns between mercury-treated and control mesocosms. In 1998, additional genetic, demographic, and environmental data were collected for the same mercury-exposed and control mesocosm populations of mosquitofish sampled in 1994 and 1996.

\section{MATERIALS AND METHODS}

\section{Mesocosms}

Eight 7,250-L mesocosms established by Mulvey et al. [5] were used in this experiment. At the termination of the Mulvey et al. [5] experiment, the mesocosms were drained and the sediments dried to ensure the elimination of all remaining mosquitofish. The four control mesocosms from the previous experiment were refilled with untreated well water $(<0.1 \mu \mathrm{g} / \mathrm{L}$ of mercury). The four mercury-treated mesocosms were also filled with untreated well water and derived all their mercury from the sediments remaining from the previous experiment. No additional mercury was added to the mesocosms for this experiment. The water levels of the mesocosms were maintained by precipitation and by addition of well water as needed. In this exposure, the water concentration of mercury remained below detectable levels ( $<0.1 \mu \mathrm{g} / \mathrm{L}$ of mercury). Whole-body concentrations of mercury in mosquitofish were used to quantify mercury exposure and assign treatment levels to the mesocosms.

\section{Fish populations}

The mosquitofish populations in the experimental mesocosms were initiated in June 1994. Mosquitofish were seined from the Risher Pond population (Barnwell County, SC, USA) on three occasions and transported to the site of the experiment. The initial mosquitofish populations were established by randomly assigning 215 mosquitofish to each of the control and mercury-treated mesocosms. A subsample $(n=134)$ of the mosquitofish collected from Risher Pond was used to determine initial allele frequencies for seven polymorphic allozyme loci in 1994. The mesocosm populations were sampled heavily in 1996 for our previous study [8], with caution taken not to harvest at levels that might be detrimental to population viability. The populations were monitored for the presence of gravid female fish during the late spring and early summer of 1998. Populations were sampled with a seine when the majority of fish were in a reproductive state in order to obtain large numbers of gravid females for fecundity analysis. All fish were frozen $\left(-70^{\circ} \mathrm{C}\right)$ until electrophoresis was performed. Fish were sexed, weighed, and measured (standard length) prior to electrophoretic analysis. Gravid females were dissected to determine the number of eggs plus developing embryos.

\section{Electrophoresis}

The following allozymes were determined using horizontal starch gel electrophoresis: fumarate hydratase (FUM, EC 4.2.1.2), mannosephosphate isomerase (MPI, EC 3.5.1.8), glucosphosphate isomerase-2 (GPI-2, EC 3.5.1.9), adenosine deaminase (ADA, EC 3.5.4.4), malate dehydrogenase-1 (MDH1, EC 1.1.1.37), and isocitrate dehydrogenase-1,2 (ICD-1 and 2, EC 1.1.1.42). Electrophoretic methods were those described previously $[5,16,17]$.

\section{Mercury analysis}

Five fish from each mesocosm were analyzed for mercury. The wet weight of each fish was recorded prior to digestion. Whole fish were digested individually using $5 \mathrm{ml}$ of trace metal-grade nitric acid in closed Teflon ${ }^{\text {(Wi }}$ vessels in a microwave oven digester (CEM, Matthews, NC, USA). The digested samples were diluted with high-purity deionized water, and bromine monochloride was added to prevent oxidation. Total mercury was determined by cold vapor atomic fluorescence spectroscopy using a model 2 analyzer (Brooks Rand, Seattle, WA, USA). All samples were analyzed within $24 \mathrm{~h}$ of digestion. All the standard materials (TORT2, lobster hepatopancreas, National Research Council of Canada, Ottawa, ON) were within the certified range of mercury concentration, and none of the blanks had detectable levels of mercury. The limit of detection was $1 \mathrm{ng} \mathrm{Hg}$, and the limit of quantification was $3 \mathrm{ng} \mathrm{Hg}$.

\section{Water quality parameters}

Common water quality parameters were measured once weekly, in the afternoon, over the course of one year (19981999) to check for differences between control and mercurytreated mesocosms that might obscure the effects of mercury exposure. The temperature, conductivity, dissolved oxygen, and $\mathrm{pH}$ were measured using a Microsonde water quality multiprobe (Hydrolab, Austin, TX, USA).

\section{Data analysis}

Allozyme frequencies and fit of observed data to HardyWeinberg expectations were calculated using BIOSYS-1 [18]. Rare alleles were pooled for Icd-1 and Gpi-2 to test for fit to Hardy-Weinberg expectations. Assessment of genetic bottlenecks was accomplished using BOTTLENECK ([19], http:// www.ensam.inra.fr/URLB/bottleneck/bottleneck.html). BOTTLENECK performs three statistical tests using allele frequency data to detect recent effective population size reductions.

Univariate statistics for standard length and weight and $t$ tests for water quality parameters were conducted using the Microsoft EXCEL spreadsheet package [20]. Differences in standard length and weight between treatments were analyzed 
Table 1. Characteristics of mosquitofish in control and mercury-exposed populations sampled in 1998. Mesocosm replicates are designated A, $\mathrm{B}, \mathrm{C}$, and D

\begin{tabular}{|c|c|c|c|c|c|c|c|c|}
\hline \multirow[b]{2}{*}{ Variable } & \multicolumn{2}{|r|}{ A } & \multicolumn{2}{|r|}{ B } & \multicolumn{2}{|r|}{$\mathrm{C}$} & \multicolumn{2}{|r|}{$\mathrm{D}$} \\
\hline & $n$ & Mean $(\mathrm{SD})^{\mathrm{a}}$ & $n$ & Mean (SD) & $n$ & Mean (SD) & $n$ & Mean (SD) \\
\hline \multicolumn{9}{|l|}{ Control mesocosms } \\
\hline \multicolumn{9}{|l|}{ Standard length $(\mathrm{mm})$} \\
\hline Female & 284 & $29.98(5.24)$ & 172 & $31.91(6.71)$ & 69 & $23.51(7.29)$ & 84 & $24.01(5.91)$ \\
\hline Male & 92 & $22.49(2.21)$ & 46 & $21.07(1.48)$ & 30 & $17.53(0.86)$ & 30 & $18.17(1.60)$ \\
\hline \multicolumn{9}{|l|}{ Weight (g) } \\
\hline Female & 284 & $0.545(0.298)$ & 172 & $0.707(0.433)$ & 69 & $0.312(0.467)$ & 84 & $0.302(0.286)$ \\
\hline Male & 92 & $0.189(0.060)$ & 46 & $0.160(0.036)$ & 30 & $0.074(0.013)$ & 30 & $0.084(0.024)$ \\
\hline Sex ratio $(\text { female }: \text { male })^{\mathrm{b}}$ & 423 & $1.49: 1$ & 224 & $3.87: 1$ & 162 & $2.38: 1$ & 167 & 4.38:1 \\
\hline Percentage mature gravid females & & 80.9 & & 98.3 & & 59.4 & & 69.0 \\
\hline Number of eggs and embryos per gravid female & 229 & $10.6(10.0)$ & 169 & $10.4(5.8)$ & 41 & $5.3(7.8)$ & 58 & $5.0(5.3)$ \\
\hline $\mathrm{Hg}$ concn. $(\mathrm{mg} / \mathrm{kg})$ & 5 & $0.14(0.01)$ & 5 & $0.06(0.02)$ & 5 & $0.07(0.03)$ & 4 & $0.07(0.01)$ \\
\hline \multicolumn{9}{|l|}{ Mercury-exposed mesocosms } \\
\hline \multicolumn{9}{|l|}{ Standard length (mm) } \\
\hline Female & 316 & $27.89(4.78)$ & 264 & $27.47(8.49)$ & 166 & $27.27(7.632)$ & 370 & $29.924(4.36)$ \\
\hline Male & 91 & $22.56(1.38)$ & 90 & $21.18(2.03)$ & 76 & $21.34(1.77)$ & 107 & $20.77(1.44)$ \\
\hline \multicolumn{9}{|l|}{ Weight (g) } \\
\hline Female & 316 & $0.409(0.237)$ & 264 & $0.479(0.421)$ & 166 & $0.427(0.411)$ & 371 & $0.522(0.252)$ \\
\hline Male & 91 & $0.168(0.030)$ & 90 & $0.152(0.039)$ & 76 & $0.126(0.026)$ & 107 & $0.112(0.027)$ \\
\hline Sex ratio $(\text { female }: \text { male })^{\mathrm{b}}$ & 558 & $1.85: 1$ & 381 & $2.66: 1$ & 279 & $2.67: 1$ & 598 & $4.59: 1$ \\
\hline Percentage mature gravid females & & 73.1 & & 67.8 & & 46.4 & & 78.0 \\
\hline Number of eggs and embryos per gravid female & 231 & $6.1(3.7)$ & 179 & $6.5(4.4)$ & 77 & $7.3(7.1)$ & 278 & $6.6(3.8)$ \\
\hline $\mathrm{Hg}$ concn. $(\mathrm{mg} / \mathrm{kg})$ & 5 & $7.96(1.49)$ & 5 & $4.27(0.14)$ & 5 & $6.17(1.01)$ & 5 & $5.04(0.71)$ \\
\hline
\end{tabular}

${ }^{a} \mathrm{SD}=$ standard deviation.

${ }^{\mathrm{b}}$ Sex ratios were calculated with the total number of mosquitofish collected from the mesocosms. The sample size for standard length and weight are a subset of the fish collected.

with a split-plot analysis of variance to control the variance due to mesocosm effects with procedure MIXED of the Statistical Analysis System [21]. Differences in total fecundity between treatments and Gpi-2 genotypes were also analyzed with procedure MIXED of the Statistical Analysis System [21]. The effects of mercury treatment and Gpi-2 genotype on the probability of female mosquitofish being gravid were analyzed using procedure LOGISTIC of the Statistical Analysis System [21].

The $\chi^{2}$ tests for nonindependence of allele frequencies between 1994, 1996, and 1998 were performed with the MINITAB statistical software package [22]. Wilcoxon rank-sum tests were used to test for differences in Gpi-2 selection coefficients, mercury concentration, and sex ratios between control and mercury-treated mesocosms with procedure NPAR1WAY of the Statistical Analysis System [21]. Selection coefficients for the GPI-2 alleles were calculated using the following formula:

$$
S=\log \left\{\left[P_{1998} /\left(1-P_{1998}\right)\right] /\left[P_{1994} /\left(1-P_{1994}\right)\right]\right\}
$$

where $S=$ the selection coefficient, $P_{1998}=$ the mesocosm population allele frequency in 1998, and $P_{1994}=$ the allele frequency of the initial population.

\section{RESULTS}

Whole-body mercury concentrations ( $\mathrm{mg} / \mathrm{kg}$ wet wt) were significantly different for fish in control and mercury-treated mesocosms ( $p=0.0001$ ) (Tables 1 and 2). Mercury concentrations for fish from control mesocosms ranged between 0.06 and $0.14 \mathrm{mg} \mathrm{Hg} / \mathrm{kg}$ wet weight. Average mercury concentrations for fish from mercury-treated mesocosms ranged between 4.27 and $7.96 \mathrm{mg} \mathrm{Hg} / \mathrm{kg}$ wet weight. No differences were observed in the average temperature, specific conductance, and $\mathrm{pH}$ between mercury-treated and control mesocosms over the course of one year (Figs. 1 and 2). Differences occurred in the dissolved oxygen concentration between control and mercury-treated mesocosms $(p=0.06)$, but the measured dissolved oxygen levels never dropped below $9 \mathrm{mg} / \mathrm{L}$ in either the control or the mercury-treated mesocosms during the daytime measurement period (Fig. 1). No dissolved oxygen measurements were made at night, when the concentrations were expected to be lowest. The available data suggest that differential anoxic stress between treatments was not probable. The similarity of measured water quality parameters between control and mercury-treated mesocosms, and the major differences in the whole-body mercury concentration between treatments, strengthens the assignment of causation of biological effects to mercury contamination.

A split-plot analysis of variance did not detect significant

Table 2. Wilcoxon rank-sum tests for Gpi-2 selection coefficients, sex ratios, and mercury concentrations in the 1998 sample

\begin{tabular}{lcrc}
\hline Variable studied & $\begin{array}{c}\text { One- or two- } \\
\text { tailed test }\end{array}$ & \multicolumn{1}{c}{$z$} & Prob $>|z|$ \\
\hline$G p i-2^{100}$ selection coefficient & One tailed & -1.587 & 0.056 \\
$G^{\prime}-2^{66}$ selection coefficient & One tailed & 1.876 & 0.031 \\
$G p i-2^{38}$ selection coefficient & One tailed & -0.722 & 0.236 \\
Sex ratio $(\text { female }: \mathrm{male})^{\mathrm{a}}$ & Two tailed & 0.144 & 0.885 \\
$\mathrm{Hg}$ concentration $(\mathrm{mg} / \mathrm{kg})^{\mathrm{a}}$ & Two tailed & -5.332 & 0.0001 \\
\hline
\end{tabular}

a Selection coefficients were not calculated for sex ratio and mercury concentration. These analyses test whether the sex ratio and mercury concentrations are the same for control and mercury-exposed populations. 

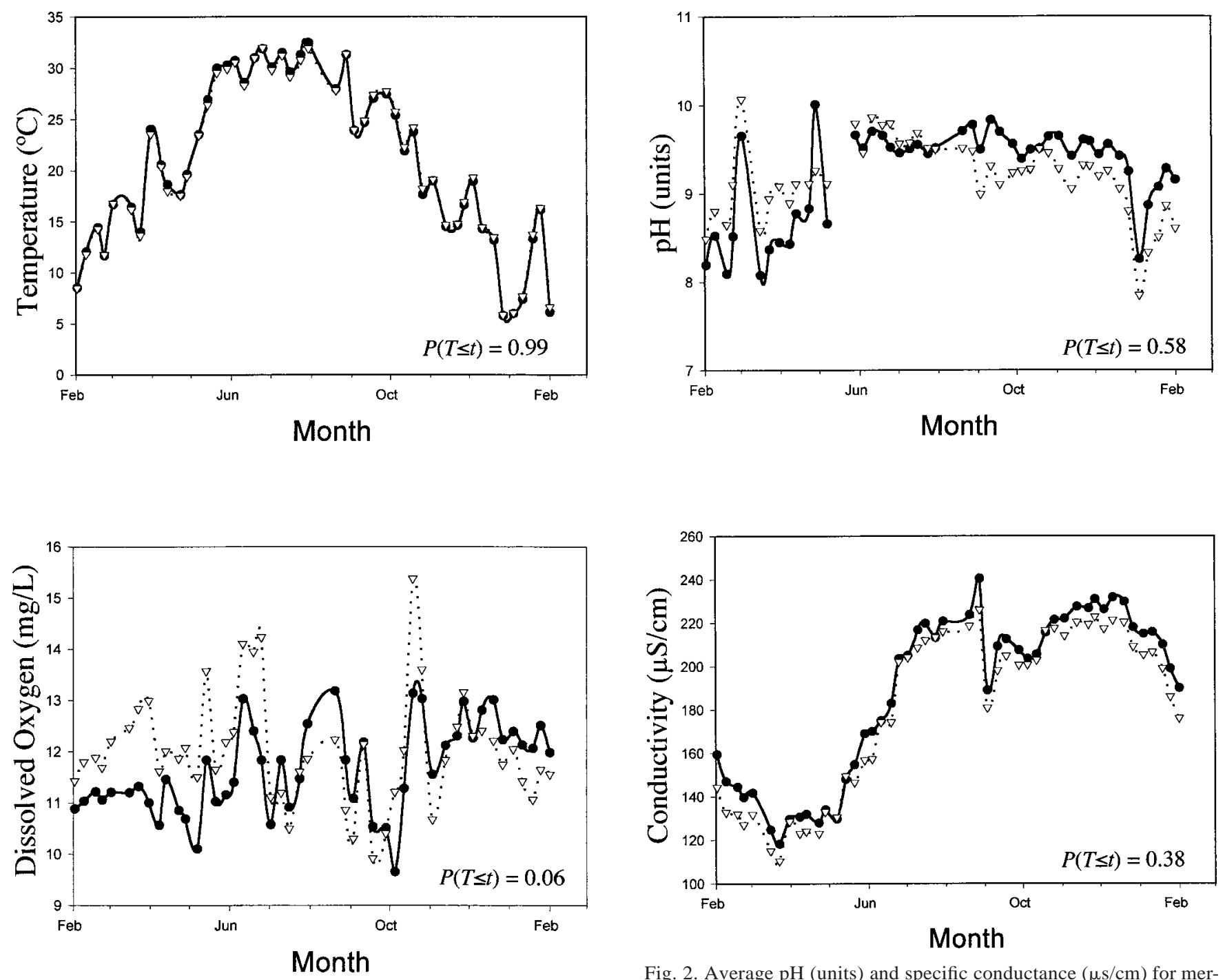

Fig. 1. Average temperature $\left({ }^{\circ} \mathrm{C}\right)$ and dissolved oxygen $(\mathrm{mg} / \mathrm{L})$ for mercury-treated and control mesocosms over a period of one year (1998-1999). Solid lines (- $(-)$ and black circles $(\bullet)$ represent control mesocosms; dotted lines $(\ldots)$ and white inverted triangles $(\nabla)$ represent mercury-treated mesocosms. The $p$ values of two-tailed $t$ tests for differences in means are indicated in the bottom-right corner of each panel.

effects of mercury treatment on standard length or weight for adult males and females in the 1998 sample. Sex ratios also differed among mesocosms but were female biased in all control and mercury-treated mesocosms (Table 1). No significant differences in sex ratio were detected between mercury-exposed and control populations (Table 2).

Allele frequencies for the initial population and seven of the eight 1998 populations were consistent with Hardy-Weinberg equilibrium expectations. (Allele frequencies for the seven allozyme loci are not reported here but are available from the primary author.) Control mesocosm A exhibited a strong departure from Hardy-Weinberg equilibrium at four allozyme loci, indicating that one or more of the assumptions underlying the Hardy-Weinberg model were not met. No evidence of genetic bottlenecks was found for seven of the eight populations. Control mesocosm A was the exception again. The results of the sign test, Wilcoxon test, and mode-shift test all indicated that this control population had undergone a recent population bottleneck and had an excess of heterozygotes.

Fig. 2. Average $\mathrm{pH}$ (units) and specific conductance ( $\mu \mathrm{s} / \mathrm{cm})$ for mercury-treated and control mesocosms over a period of one year (19981999). Solid lines (—) and black circles $(\bullet)$ represent control mesocosms; dotted lines $(\ldots)$ and white inverted triangles $(\nabla)$ represent mercury-treated mesocosms. The $p$ values of two-tailed $t$ tests for differences in means are indicated in the bottom-right corner of each panel.

Allele frequencies for the Icd-1, Icd-2, Mpi, Ada, Mdh, and Fum loci were homogenous for the initial, 1996, and 1998 samples. Chi-square tests of homogeneity of allele frequencies between initial, 1996, and 1998 samples revealed significant changes in allele frequencies at the Gpi-2 locus in five of eight mesocosms $(p=0.04)$. The significant change in allele frequencies at the Gpi-2 locus prompted calculation of selection coefficients for the three Gpi-2 alleles by mesocosm. Analysis of selection coefficients indicated a decrease in the Gpi-2 ${ }^{100}$ allele $(p=0.056)$ and a corresponding increase in the Gpi-266 allele $(p=0.031)$ in mercury-exposed mosquitofish populations. No selection was noted for the rare $G p i-2^{38}$ allele ( $p=$ 0.236 )(Table 2). The changes in Gpi-2 allele frequencies associated with mercury exposure are illustrated in Figure 3. Additionally, the Gpi-2100 and Gpi-266 allele frequencies displayed greater variance among mercury-exposed populations than control populations (Fig. 3). Greater variance was observed among Gpi-2 $2^{38}$ allele frequencies in the control populations than in the mercury-treated populations (Fig. 3). The 

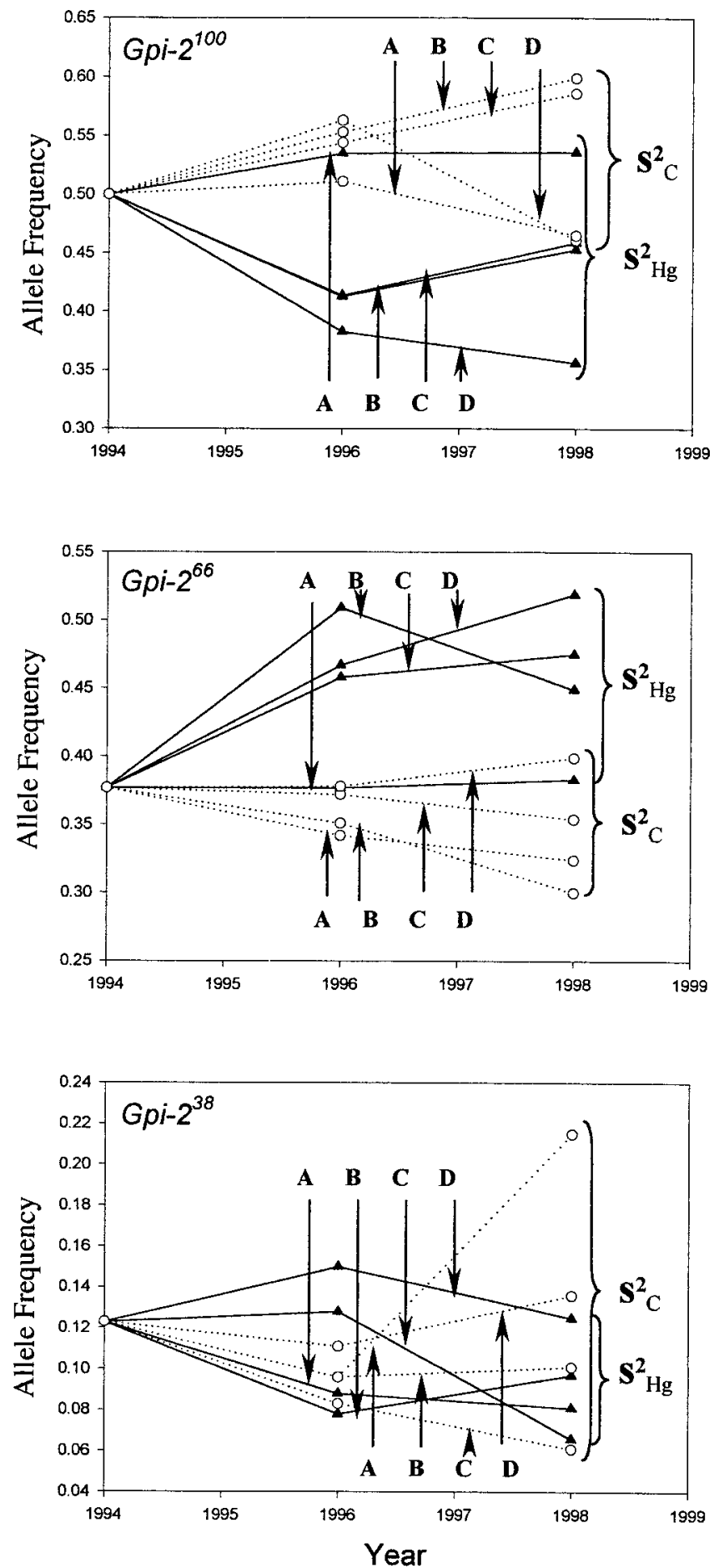

Fig. 3. Change in the frequencies of Gpi-2 alleles over four years ( $~$ eight generations) in experimental mosquitofish populations. Solid lines (-) with solid triangles $(\mathbf{\Lambda})$ denote mercury-exposed populations; dotted lines $(. .$.$) with open circles (\bigcirc)$ denote control populations. Lines are labeled A, B, C, or D corresponding to mesocosm designations in Table 1. Allele plotted is designated in the upper-left corner of each panel. All alleles except $G p i-2^{38}$ exhibit greater sample variance among mercury-exposed populations $\left(s_{\mathrm{Hg}}^{2}\right)$ than among control populations $\left(s_{C}^{2}\right)$.

Gpi-2 allele frequencies for each mesocosm population are reported in Table 3 .

The results of a logistic regression indicated that mercuryexposure $(p=0.001)$ but not Gpi-2 genotype $(p=0.25)$ influenced the probability of a female mosquitofish being grav- id. Mercury-exposed females had a lower probability of being gravid. Analysis of the total fecundity data (number of eggs + embryos) indicated that mercury exposure $(p=0.04)$ as well as female mass $(p=0.001)$ influenced total fecundity. No Gpi-2 genotype effects on total fecundity were observed. Mercury exposure reduced the number of eggs or developing embryos within a female (Table 1), and fecundity increased as female mass increased.

\section{DISCUSSION}

Seven of the populations had genotype frequencies that did not deviate from those expected under Hardy-Weinberg equilibrium. However, control population A deviated from HardyWeinberg expectations at four allozyme loci, indicating that one or more assumptions underlying the Hardy-Weinberg principle had been violated. Most of the Hardy-Weinberg model assumptions had been met through the experimental design. It is possible that nonrandom mating, overlapping generations, or small population size could have produced a departure from Hardy-Weinberg equilibrium frequencies. Statistical tests indicated a bottleneck (recent reduction in effective population size) in this population. The bottleneck could have resulted from overharvesting during the 1996 collection period. The bottleneck did not grossly affect the allele frequencies at the Gpi-2 locus. The Gpi-2 ${ }^{100}$ and Gpi-2 ${ }^{66}$ allele frequencies of control population A were similar to the other control populations. However, the Gpi-2 $2^{38}$ allele frequency in control population A was much higher than the other control populations (Fig. 3 and Table 3).

The changes in the Gpi-2 allele frequencies displayed temporal stability in both the control and the mercury-treated populations. In the control and original Risher Pond populations, $G p i-2^{100}$ had the highest allele frequency, followed by Gpi-266. The Gpi-2 $2^{38}$ allele was the least common allele. The Gpi-2 allele frequencies in mercury-exposed populations changed from the initial Gpi-2 allele frequencies and were different from control Gpi-2 allele frequencies. The Gpi-2 ${ }^{66}$ allele frequency increased in three of four mercury-exposed populations and became the most common allele in two of four populations. The increase in the $G p i-2^{66}$ allele frequency was accompanied by a corresponding decrease in the Gpi-2 ${ }^{100}$ allele frequency in mercury-exposed populations. The Gpi-238 allele showed no consistent pattern over four years in either control or mercuryexposed populations.

All mercury-exposed populations did not exhibit the same response at the Gpi-2 locus. Over the four-year study period, mercury-exposed population A showed an increase in the $G p i-2^{100}$ allele frequency instead of an increase in the Gpi-2 $2^{66}$ allele frequency. Although all the allele frequencies showed slight changes over time in each population, the overall patterns of Gpi-2 allele frequencies remained consistent with the 1996 sample, even for the mercury-exposed population that deviated from the average response. The results of the current and previous mesocosm studies indicate that, in general, the changes in allele frequencies associated with mercury exposure are temporally stable in chronically contaminated environments. The temporal stability of Gpi-2 allele frequencies in the mercury-exposed mesocosm populations is also consistent with the temporal stability of allele frequencies reported in mosquitofish populations from the Savannah River drainage [23].

The Gpi-266 and Gpi-2 ${ }^{100}$ allele frequency shifts observed in the present study were similar to the frequency shifts pre- 
Table 3. Allele frequencies at the Gpi-2 locus for the 1994 and 1998 samples

\begin{tabular}{|c|c|c|c|c|c|c|c|c|c|}
\hline \multirow[b]{3}{*}{ Allele } & \multirow{3}{*}{$\begin{array}{c}1994 \\
\text { Initial }\end{array}$} & \multicolumn{8}{|c|}{1998} \\
\hline & & \multicolumn{4}{|c|}{ Control mesocosms } & \multicolumn{4}{|c|}{ Mercury-exposed mesocosms } \\
\hline & & A & B & $\mathrm{C}$ & $\mathrm{D}$ & A & B & $\mathrm{C}$ & $\mathrm{D}$ \\
\hline$n$ & 134 & 375 & 218 & 99 & 114 & 407 & 354 & 242 & 468 \\
\hline$G p i-2^{100}$ & 0.493 & 0.461 & 0.599 & 0.586 & 0.465 & 0.536 & 0.453 & 0.459 & 0.356 \\
\hline$G p i-2^{66}$ & 0.381 & 0.324 & 0.300 & 0.354 & 0.399 & 0.383 & 0.449 & 0.475 & 0.519 \\
\hline Gpi-2 ${ }^{38}$ & 0.127 & 0.215 & 0.101 & 0.061 & 0.136 & 0.081 & 0.097 & 0.066 & 0.125 \\
\hline
\end{tabular}

dicted using computer models of mercury-exposed mosquitofish populations [9]. The simulations modeled viability, sexual, and fecundity selection during mercury exposure and included the effects of genetic drift and immigration. The relative fitnesses of the Gpi-2 genotypes were quantified on the basis of previous studies $[4,5,16,24]$ and used as model parameters in the simulations. Changes in allele frequencies were predicted in response to periodic acute mercury exposures of 1.0 $\mathrm{mg} / \mathrm{L}$ combined with chronic mercury exposure between acute episodes.

The simulations indicated that the Gpi-2 ${ }^{100}$ allele was replaced by the Gpi-266 allele as the most common allele in mercury-exposed populations after approximately 15 generations and that the Gpi-2 $2^{38}$ allele would be lost from the population under the pulsed exposure scenario [9]. In the present study, the Gpi-2 $2^{38}$ allele decreased from its initial frequency in all four mercury-exposed populations after four years and approximately eight generations. However, the Gpi-2 $2^{38}$ allele decreased from its initial allele frequency in two control mesocosms during the same time period (Fig. 3 and Table 3). Elimination of the Gpi-2 $2^{38}$ allele in mercury-exposed mesocosm populations was unlikely to occur as predicted by the model [9] because the populations did not experience the periodic mercury exposures $\left(1 \mathrm{mg} / \mathrm{L}_{\text {as }} \mathrm{Hg}^{2+}\right)$ required to produce differential acute mortality of the $G p i-2^{38 / 38}$ genotype. Continual surveillance and sampling indicated that episodic acute mortality did not occur in the mercury-exposed mesocosm populations. The model correctly predicted $\mathrm{Gpi}-2^{66}$ replacing Gpi-2 $2^{100}$ as the most common allele in mercury-exposed populations, providing indirect support that reproductive components of selection (sexual selection and fecundity selection) are at least as important as viability selection in determining the genetic composition of populations exposed to toxicants. The shifts in Gpi-2 allele frequencies in the mercury-exposed mesocosm populations were not dependent on acute exposure duration, as observed in the model.

Investigation of the reproductive components of fitness can provide insight about which population-level processes are responsible for observed changes in allele frequencies [11,25] and is often accomplished through selection component analysis or analysis of reproductive data. Nadeau and Baccus [26] summarized the results of six published studies using selection component analysis indicating evidence of selection in natural populations. Selection for reproductive components of fitness was more common than zygotic selection (survival) and was observed in every study but one. At least five laboratory studies with Drosophila species have also demonstrated that reproductive components of fitness are often much more important than viability [11]. A previous mesocosm study of mosquitofish populations found female sexual selection and fecundity selection in mercury-exposed populations [5]. Fe- males homozygous for the Gpi-2100 allele had a lower probability of being gravid and fewer developing embryos. The results of the previous study [5] prompted investigation of the reproductive characteristics of female mosquitofish in this study to help determine a mechanism that might explain the observed changes in Gpi-2 allele frequencies.

The effects of toxicants on reproduction are commonly investigated in fish species $[5,27,28]$. In the present study, chronic exposure to mercury reduced the likelihood of a female mosquitofish being gravid. Mercury-exposed female mosquitofish also carried fewer eggs or embryos than control mosquitofish. Given the changes in Gpi-2 allele frequencies [8] and female sexual selection and fecundity selection at the Gpi-2 locus [5], we hypothesized that differences in reproductive fitness among Gpi-2 genotypes might help explain the allele patterns observed in the 1998 sample. In this study, Gpi-2 genotype did not influence fecundity or the likelihood of being gravid.

It is possible that the selective action of mercury on the Gpi-2 locus might be too small to measure over one generation but still change allele frequencies over several generations of exposure. This could explain our inability to detect female reproductive fitness differences among Gpi-2 genotypes, as our study only measured reproductive fitness over one generation. Other components of selection might be acting in the mercury-exposed populations, such as male sexual selection, gametic selection, and viability selection. These types of selection would be difficult to measure directly in mesocosm studies. Another possibility is that Gpi-2 is linked to an unknown locus that is undergoing a different type of selection than the types investigated in this study.

Taken as a whole, the results of the current and previous studies $[5,8]$ of mosquitofish populations exposed to mercury in mesocosms indicate that changes in allozyme frequencies can indicate population-level effects of toxicants. The combined studies have provided much needed information for the assessment of biomonitoring of natural populations using allozymes. These studies have eliminated or reduced the effects of confounding abiotic variables (e.g., differential water quality) and biotic variables (e.g., founder effects, migration, predation, genetic clines) and have strengthened the assignment of causation to mercury exposure. The use of mesocosms also enabled true replication and true controls, thereby eliminating reliance on reference populations. Associated studies have investigated survival $[16,17,24]$ and other aspects of population biology [5] in an attempt to understand the causes of the changes in Gpi-2 allele frequencies. Correlation between response to contaminants and allozyme genotype have been documented for diverse taxa and a wide range of chemicals and environmental stressors $[1-8,12,14-17,24]$, indicating that changes in allozyme frequency have general utility. The current study has 
shown that changes in allele frequencies of exposed populations can remain temporally stable, thus reinforcing their utility as bioindicators to environmental scientists.

Allozyme analysis complements the existing methodologies for determining the impact of toxicants on populations but may not be effective as the sole indicator of population response to environmental contaminants. The results of this and our previous mesocosm study [8] indicate that changes in allozyme frequencies of toxicant-exposed populations are associated with stochastic processes and that deviations from the predicted response occur. Effective use of allozyme data requires that the ecology and genetic history of the exposed populations be understood so that population response is properly attributed to toxicants instead of confounding ecological and biological factors.

Acknowledgement-Research and manuscript preparation was supported by Financial Assistance Award Number DE-FC09-96SR18546 from the U.S. Department of Energy to the University of Georgia Research Foundation. The authors would like to thank P. Shaw-Allen, M. Komoroski, G. Plague, P. Johns, H. Brant, M. Eliot, and T. Phillipi. Electrophoretic data were collected in the laboratory of M. Smith. Mercury analyses were conducted in the laboratory of C. Jagoe.

\section{REFERENCES}

1. Nevo E, Ben-Shlomo R, Lavie B. 1984. Mercury selection of allozymes in marine organisms: Prediction and verification in nature. Proc Natl Acad Sci USA 81:1258-1259.

2. Gillespie RB, Guttman SI. 1989. Effects of contaminants on the frequencies of allozymes in populations of the central stoneroller. Environ Toxicol Chem 8:309-317.

3. Hughes JM, Harrison DA, Arthur JM. 1991. Genetic variation at the Pgi locus in the mosquitofish Gambusia affinis (Poecilidae) and a possible effect on susceptibility to an insecticide. Biol J Linn Soc 44:153-167.

4. Heagler MG, Newman MC, Mulvey M, Dixon PM. 1993. Allozyme genotype in mosquitofish, Gambusia holbrooki, during mercury exposure: Temporal stability, concentration effects and field verification. Environ Toxicol Chem 12:385-395.

5. Mulvey M, Newman MC, Chazal A, Keklak MM, Heagler MG, Hales LS. 1995. Genetic and demographic responses of mosquitofish (Gambusia holbrooki Girard 1859) populations stressed by mercury. Environ Toxicol Chem 14:1411-1418.

6. Roark S, Brown K. 1996. Effects of metal contamination from mine tailings on allozyme distributions of populations of Great Plains fishes. Environ Toxicol Chem 15:921-927.

7. Sloss BL, Romano MA, Anderson RV. 1998. Pollution-tolerant allele in fingernail clams (Musculium transversum). Arch Environ Contam Toxicol 35:302-308.

8. Tatara CP, Mulvey M, Newman MC. 1999. Genetic and demographic responses of mosquitofish (Gambusia holbrooki) populations exposed to mercury for multiple generations. Environ Toxicol Chem 18:2840-2845.

9. Newman MC, Jagoe RH. 1998. Allozymes reflect the populationlevel effect of mercury: Simulations of the mosquitofish ( $\mathrm{Gam}$ - busia holbrooki Girard) GPI-2 response. Ecotoxicology 7:141150.

10. Endler JA. 1986. Natural Selection in the Wild. Princeton University Press, Princeton, NJ, USA.

11. Hartl DL, Clark AG. 1989. Principles of Population Genetics. Sinauer Associates, Sunderland, MA, USA.

12. Gillespie RB, Guttman SI. 1999. Chemical-induced changes in the genetic structure of populations: Effects on allozymes. In Forbes VE, ed, Genetics and Ecotoxicology. Taylor \& Francis, Philadelphia, PA, USA, pp 55-77.

13. Guttman SI. 1994. Population genetic structure and ecotoxicology. Environ Health Perspect 102(Suppl 12):97-100.

14. Mulvey M, Keller GP, Meffe GK. 1994. Single and multiplelocus genotypes and life-history responses of Gambusia holbrooki reared at two temperatures. Evolution 48:1810-1819.

15. Congdon BC. 1994. Salinity fitness differences amongst GPI genotypes in the mosquitofish Gambusia holbrooki (Poeciliidae: Teleostei). Biol J Linn Soc 53:343-352.

16. Newman MC, Diamond SA, Mulvey M, Dixon PM. 1989. Allozyme genotype and time to death of mosquitofish, Gambusia affinis (Baird and Girard) during acute toxicant exposure: A comparison of arsenate and inorganic mercury. Aquat Toxicol 15: 141-156.

17. Heagler MG, Newman MC, Mulvey M, Dixon PM. 1993. Allozyme genotype in mosquitofish, Gambusia holbrooki, during mercury exposure: Temporal stability, concentration effects and field verification. Environ Toxicol Chem 12:385-395.

18. Swofford DL, Selander RB. 1981. BIOSYS-1: A FORTRAN program for the comprehensive analysis of electrophoretic data in population genetics and systematics. J Hered 72:282-283.

19. Cornuet JM, Luikart G. 1997. Description and power analysis of two tests for detecting recent population bottlenecks from allele frequency data. Genetics 144:2001-2014.

20. Microsoft. 1994. Microsoft Excel User's Guide, Ver 5.0. Redmond, WA, USA.

21. SAS Institute. 1987. SAS/STAT ${ }^{\circledR}$ Guide for Personal Computers, Ver 6 ed. Cary, NC, USA.

22. Minitab. 1995. Minitab User's Guide, Release 10 Xtra. State College, PA, USA.

23. McClenaghan LR Jr, Smith MH, Smith MW. 1985. Biochemical genetics of mosquitofish. IV. Changes of allele frequencies through time and space. Evolution 39:451-460.

24. Diamond SA, Newman MC, Mulvey M, Dixon PM, Martinson D. 1989. Allozyme genotype and time to death of mosquitofish, Gambusia affinis (Baird and Girard) during acute exposure to inorganic mercury. Environ Toxicol Chem 8:613-622.

25. Christianen FB, Frydenberg O. 1973. Selection component analysis of natural polymorphisms using population samples that include mother-offspring combinations. Theor Popul Biol 4:425445.

26. Nadeau JH, Baccus R. 1981. Selection components of four allozymes in natural populations of Peromyscus maniculatus. Evolution 35:11-20.

27. Black DE, Guthjar-Gobell R, Pruell RJ, Bergen B, McElroy AE. 1998. Effects of a mixture of non-ortho- and mono-ortho-polychlorinated biphenyls on reproduction in Fundulus heteroclitus (Linnaeus). Environ Toxicol Chem 17:1396-1404.

28. White PA, Robitaille S, Rasmussen JB. 1999. Heritable reproductive effects of benzo[a]pyrene on the fathead minnow (Pimephales promelas). Environ Toxicol Chem 18:1843-1847. 